\title{
A comparative study of low dose magnesium sulphate (Dhaka regime) and Pritchard regime for the management of impending eclampsia and eclampsia
}

\author{
Ranjana $^{1 *}$, Abha Rani Sinha1, Chandra Prakash²
}

\author{
${ }^{1}$ Department of Obstetrics and Gynecology, Patna Medical College and Hospital, Patna, Bihar, India \\ ${ }^{2}$ Department of Anaesthesiology, Indira Gandhi Institute of Medical Sciences, Seikhpura, Patna, Bihar, India
}

Received: 22 April 2017

Accepted: 28 April 2017

\author{
*Correspondence: \\ Dr. Ranjana, \\ E-mail: rranjana24@gmail.com
}

Copyright: $\odot$ the author(s), publisher and licensee Medip Academy. This is an open-access article distributed under the terms of the Creative Commons Attribution Non-Commercial License, which permits unrestricted non-commercial use, distribution, and reproduction in any medium, provided the original work is properly cited.

\begin{abstract}
Background: Eclampsia is a common obstetrical emergency though preventable, yet remains a leading cause of maternal and perinatal morbidity and mortality in the developing world. Pritchard regime is most widely used magnesium sulphate regime for control of eclamptic fits but its dose related toxicity is a major concern among Indian women with low BMI and at peripheral institutions where the patients monitoring is limited. The objective was to study the efficacy of low dose $\mathrm{MgSO}_{4}$ regime (Dhaka regime) for control of convulsions in eclampsia and prevention of convulsions in impending eclampsia, to assess the magnesium related toxicity and to analyze the maternal and perinatal outcomes as compared to standard Pritchard regime.

Methods: This prospective study was carried out in the Department of obstetrics and Gynaecology at Patna Medical College and Hospital, Patna. Study was done on 80 patients of eclampsia and impending eclampsia. Patients were divided into two groups A and B. Group A ( $\mathrm{n}=40)$ received low dose $\mathrm{MgSO}_{4}$ regime (Dhaka regime) and Group B $(\mathrm{n}=40)$ received standard Pritchard regime. Results were analysed using statistical package of social sciences (SPSS) 21.0. Statistical significance was set at $\mathrm{p} \leq 0.05$.

Results: In the present study, convulsions were controlled in $95 \%$ of eclampsia cases with low dose magnesium sulphate (Dhaka) regime. Recurrence of convulsion was seen in both groups. None of the patients with impending eclampsia in both the groups developed the seizure during entire treatment period. Signs of impending $\mathrm{MgSO}_{4}$ toxicity and the mean amount of magnesium sulphate received was found more in Pritchard regime group (22.5gms in Group A and 39gms in Group B) and was statistically significant with $\mathrm{p}$ value $<0.001$. There were 3 maternal deaths in present study.

Conclusions: Low dose magnesium sulphate is as effective as standard Pritchard regime in controlling the eclamptic fits and preventing its recurrence with comparable maternal and perinatal outcome and less chances of magnesium toxicity. This regimen may be more suitable for use in Indian women with low BMI and in resource poor settings where clinical monitoring is limited.
\end{abstract}

Keywords: Eclampsia, Low dose magnesium sulphate (Dhaka regime) regime, $\mathrm{MgSO}_{4}$, Pritchard regime

\section{INTRODUCTION}

Eclampsia is one of the most common obstetrical emergencies that cause significant maternal and perinatal morbidity and mortality especially in the developing world. The first principal in the management of Eclampsia is the control of convulsions. Magnesium sulphate is the anticonvulsant drug of choice which prevents and controls eclamptic fits and hence reduces maternal and neonatal morbidity but its dose related 
toxicity is a major concern particularly in clinical environments where the capacity for patient monitoring is limited and when recipients are of small built. ${ }^{1-3}$ Different magnesium sulphate dose protocols have been used in treating Eclampsia, amongst which Pritchard regime is widely used. ${ }^{4}$

Women in India, especially from rural areas or from low socio-economic Strata, tend to have smaller weights. Administrating Pritchard regime might prove to be hazardous in these low weight women and there is possibility of most dreadful respiratory failure. ${ }^{5}$ With this in mind, many studies have been conducted to determine the lowest effective dose and these modifications have shown promise in terms of decreased side effects and comparable efficacy. ${ }^{6-8}$

Flower etal adjusted dose of magnesium sulphate according to body weight, plasma level and urinary excretion of magnesium sulphate. ${ }^{6}$ Sardesai et al used low dose magnesium sulphate regimen in Eclampsia in Indian women and found to be very effective and safe..$^{5}$

The aim of the present study was to evaluate the efficacy of low dose $\mathrm{MgSO}_{4}$ regime (Dhaka regime) for control of convulsions in eclampsia and prevention of convulsions in impending eclampsia, to assess the magnesium related toxicity and to analyze the maternal and perinatal outcomes as compared to standard Pritchard regime.

\section{METHODS}

This prospective study was carried out in the department of obstetrics and Gynaecology, Patna Medical College and Hospital, Patna from January 2012 to January 2014 after taking approval from the Institutional Ethical Committee. 80 cases of impending eclampsia, ante partum, intrapartum and postpartum eclampsia were included in the study. Cases who had already received either magnesium sulphate or any other anticonvulsant treatment before admission to our hospital, other causes of convulsions like epilepsy, meningitis, encephalitis, cerebral tumours, metabolic abnormalities, and those who presented with complications like cerebrovascular accidents, renal failure, aspiration pneumonitis and HELLP syndrome were excluded from the study.

Written informed consent was obtained in all the cases. All the patients included in the study were subjected to detailed history and thorough clinical examination including general physical, obstetrical and systemic examination. History was elicited from the patient and her attendants if she was brought in a post ictal state or unconscious state.

History regarding her age, parity, booking status, gestational age, number of eclamptic fits before admission, whether she was a known case of pregnancy induced hypertension or chronic hypertension, whether she was on anti-hypertensive drugs, presence of oedema if so how long, existence of imminent symptoms like headache, vomiting, severe epigastric pain, blurring of vision were all elicited thoroughly. BMI was calculated from her old records in booked cases otherwise at the time of admission after stabilizing the patients. Any known history of epilepsy, renal failure, heart block was also elicited in a detailed manner. All the investigations including $\mathrm{ABO}$ and $\mathrm{Rh}$ type, complete hemogram including peripheral smear to see any evidence of haemolysis, liver function tests, kidney function tests, coagulation profile, Fundus examination and urine analysis for proteinuria were done.

All 80 cases were divided in to two groups. GroupA received low dose $\mathrm{MgSO}_{4}$-Dhaka regimen. This comprised of a loading dose of 4 grams of $\mathrm{MgSO}_{4}$ intravenous in dilution and 3 grams intramuscular (i.m) in each buttock (10 grams). A maintenance dose of 2.5 grams (IM) was given 4 hourly in alternate buttock. Cases in group $\mathrm{B}$ received $\mathrm{MgSO}_{4}$ as per Pritchard regimen. This included a loading dose of 4 grams intravenously in dilution and 5 grams of magnesium sulphate deep IM in each buttock (14 grams). Subsequently 5 grams of $\mathrm{MgSO}_{4}$ were given deep IM every 4 hourly in alternate buttock. In both the groups, drug was continued for 24 hours after the delivery or last seizure, whichever was later.

Evidence of impending magnesium toxicity was detected by observing respiratory rate, Patellar reflexes and urinary output four hourly. Maintenance dose was skipped if patellar reflexes were absent, respiratory rate was $<16$ per minute or urinary output less than $30 \mathrm{ml}$ per hour and serum magnesium was sent for detecting magnesium toxicity. If seizures reappeared or were not controlled in patients receiving Dhaka regimen, additional dose of 2 gm IV slowly magnesium sulphate was given, and if again seizure reappeared case was shifted to standard Pritchard regimen. In Pritchard regime group, for control of recurrence of convulsion, same additional dose of $2 \mathrm{gm}$ IV magnesium sulphate was given and if convulsion was still not controlled with this, IV phenytoin was given.

Labetalol injection was given as antihypertensive when the diastolic blood Pressure was more than $110 \mathrm{~mm}$ of $\mathrm{Hg}$, in the initial dose of $20 \mathrm{mg}$ intravenously; it was then increased to $40 \mathrm{mg}$ after 20 minutes or further to $80 \mathrm{mg}$ if needed. The aim was to bring the diastolic blood pressure $\leq 100 \mathrm{~mm}$ of $\mathrm{Hg}$. Hydration was maintained by ringer lactate solution $1000 \mathrm{cc}$ over 24 hours and intravenous fluids were restricted to prevent circulatory overload. Patients were encouraged to take fluid orally as soon as they recovered consciousness.

Termination of pregnancy was undertaken in all cases of impending eclampsia and eclampsia. Delivery was expedited in the form of induction/augmentation of labour or L.S.C.S depending upon Bishop's score, gestational age and viability of the foetus. 
The primary objective of the study was to compare the efficacy and safety of low dose regimen (Dhaka regime) in the management of eclampsia and impending eclampsia as compared to standard Pritchard regimen. Maternal complications and perinatal outcome was taken as a secondary objective in both groups. Baby was managed by paediatrician following vaginal delivery or caesarean section till discharge. Postnatally blood pressure monitoring was continued and tab. Labetalol and or amlodipine were used as antihypertensive drug.

\section{Statistical analysis}

Date of individual case was entered in MS Excel sheet and was analyzed using statistical package of social sciences (SPSS) 21.0. Statistical significance was set at $\mathrm{p} \leq 0.05$.

\section{RESULTS}

The mean age of the patients was $25.8 \pm 3.43$ years in Group A and 25.7 \pm 3.53 years in Group B.

Most women were of small stature, with a mean height of $154 \pm 0.04 \mathrm{~cm}$ in Group A and $156 \pm 0.03 \mathrm{~cm}$ in Group B, a mean weight of $48.7 \pm 4.72 \mathrm{~kg}$ in Group $\mathrm{A}$ and $48.9 \pm 7.02$ $\mathrm{kg}$ in Group B, and a mean body mass index (calculated as weight in kilograms divided by the square of height in meters) of $20.31 \pm 1.34 \mathrm{~kg} / \mathrm{m}^{2}$ and $19.99 \pm 2.15 \mathrm{~kg} / \mathrm{m}^{2}$ in Group A and Group B respectively.

$75 \%$ of cases in group A and $65 \%$ of cases in group B were unbooked and had no antenatal records at the time of admission to our hospital. Majority of patients were primigravida $(70 \%$ and $75 \%$ in group A and group B respectively). Ante partum eclampsia was the most common followed by impending eclampsia in both the groups. Mean gestational age in Group A was $34.5 \pm 2.88$ weeks and in Group B was $34.8 \pm 2.71$ weeks. At the time of admission, majority of patients were having number of fits between $1-5$ in both the group $(67.5 \%$ in group A and $57.5 \%$ in group B). Only one patient experienced more than 10 fits in group B (Table 1).

Convulsions were controlled in $95 \%$ of cases with Dhaka regime and $97.5 \%$ of cases with Pritchard regime. Recurrence of convulsion was seen in two cases of low dose magnesium sulphate (Dhaka regime) and in one case of Pritchard regime which were tried to control by a single additional dose of 2 grams of $20 \% \mathrm{MgSO}_{4}$ given intravenously.

One cases responded but another case of Dhaka regime had further reoccurrence of convulsion, which was considered as failure of regime and the case was immediately shifted to standard Pritchard regime.

In Pritchard regime group, there was further convulsion after giving 2 grams of $20 \% \mathrm{MgSO}_{4}$ intravenously for which IV phenytoin was given (Table 2).
Table 1: Patients characteristics in the two groups.

\begin{tabular}{|c|c|c|}
\hline $\begin{array}{l}\text { Age group } \\
\text { (years) }\end{array}$ & $\begin{array}{l}\text { Dhaka regime } \\
\text { Group A }\end{array}$ & $\begin{array}{l}\text { Pritchard } \\
\text { regime } \\
\text { Group B }\end{array}$ \\
\hline & $n=40$ & $n=40$ \\
\hline$<20$ & $1(2.5 \%)$ & $2(5 \%)$ \\
\hline $20-25$ & $22(55 \%)$ & $20(50 \%)$ \\
\hline $26-30$ & $13(32.5 \%)$ & $15(37.5 \%)$ \\
\hline $31-35$ & $4(10 \%)$ & $3(7.5 \%)$ \\
\hline Mean age (years) & $25.8 \pm 3.43$ & $25.7 \pm 3.53$ \\
\hline $\begin{array}{l}\text { Mean weight } \\
(\mathrm{Kg})\end{array}$ & $48.7 \pm 4.72$ & $48.9 \pm 7.02$ \\
\hline Mean height $(\mathrm{cm})$ & $154 \pm 0.04$ & $156 \pm 0.03$ \\
\hline $\begin{array}{l}\text { Mean } \\
\text { BMI }\left(\mathrm{Kg} / \mathrm{m}^{2}\right)\end{array}$ & $20.31 \pm 1.34$ & $19.99 \pm 2.15$ \\
\hline \multicolumn{3}{|l|}{ Booked/unbooked } \\
\hline Booked & $10(25 \%)$ & $14(35 \%)$ \\
\hline Unbooked & $30(75 \%)$ & $26(65 \%)$ \\
\hline \multicolumn{3}{|l|}{ Parity } \\
\hline Primigravida & $28(70 \%)$ & $30(75 \%)$ \\
\hline Multigravida & $12(30 \%)$ & $10(25 \%)$ \\
\hline \multicolumn{3}{|l|}{ Gestational age } \\
\hline$<28$ weeks & $2(5 \%)$ & $1(2.5 \%)$ \\
\hline 28-32 weeks & $4(10 \%)$ & $5(12.5 \%)$ \\
\hline 32-36 weeks & $18(45 \%)$ & $14(35 \%)$ \\
\hline$>36$ weeks & $16(40 \%)$ & $20(50 \%)$ \\
\hline $\begin{array}{l}\text { Mean gestational } \\
\text { age (weeks) }\end{array}$ & $34.5 \pm 2.88$ & $34.8 \pm 2.71$ \\
\hline \multicolumn{3}{|l|}{ Type of eclampsia } \\
\hline Impending & $8(20 \%)$ & $10(25 \%)$ \\
\hline Ante partum & $22(55 \%)$ & $19(47.5 \%)$ \\
\hline Intra partum & $4(10 \%)$ & $6(15 \%)$ \\
\hline Post-partum & $6(15 \%)$ & $5(12.5 \%)$ \\
\hline \multicolumn{3}{|l|}{ No. of fits } \\
\hline $1-5$ & $27(67.5 \%)$ & $23(57.5 \%)$ \\
\hline $5-10$ & $5(12.5 \%)$ & $6(15 \%)$ \\
\hline$>10$ & $0(0 \%)$ & $1(2.5 \%)$ \\
\hline
\end{tabular}

Table 2: Efficacy of Pritchard regime and Dhaka regime to control convulsions.

\begin{tabular}{|lll|}
\hline Outcome & $\begin{array}{l}\text { Dhaka } \\
\text { regime } \\
(\mathrm{n}=40)\end{array}$ & $\begin{array}{l}\text { Pritchard } \\
\text { regime } \\
(\mathrm{n}=40)\end{array}$ \\
\hline $\begin{array}{l}\text { Convulsions controlled } \\
38(95 \%)\end{array}$ & $39(97.5 \%)$ \\
\hline $\begin{array}{l}\text { Recurrence of convulsion } \\
\text { Additional 2 gram IV dose }\end{array}$ & $02(5 \%)$ & $1(2.5 \%)$ \\
$\begin{array}{l}\text { of } \mathrm{MSO}_{4} \text { required for } \\
\text { control of recurrent }\end{array}$ & $02(5 \%)$ & $1(2.5 \%)$ \\
\hline $\begin{array}{l}\text { Recurrence of convulsion } \\
\text { after additional } 2 \text { gram IV } \\
\text { dose of } \mathrm{MgSO}_{4}\end{array}$ & $1(2.5 \%)$ & $1(2.5 \%)$ \\
\hline \begin{tabular}{l} 
Failure of regimen \\
\hline
\end{tabular} & $1(2.5 \%)$ & $1(2.5 \%)$ \\
\hline
\end{tabular}

The mean amount of magnesium sulphate received was 22.5 gms and 39 gms in Group A and Group B 
respectively in patients with impending eclampsia and eclampsia and was statistically significant with a $\mathrm{p}$ value $<0.001$ (Table 3).

Table 3: Dose of magnesium sulphate received.

\begin{tabular}{|ll|l|}
\hline $\begin{array}{l}\text { Total dose } \\
(\mathrm{gms})\end{array}$ & $\begin{array}{l}\text { Dhaka regime } \\
(\mathbf{n = 4 0})\end{array}$ & $\begin{array}{l}\text { Prichard } \\
\text { regime }(\mathbf{n = 4 0})\end{array}$ \\
\hline$<15$ & $4(10 \%)$ & $0(0 \%)$ \\
\hline $16-20$ & $6(15 \%)$ & $4(10 \%)$ \\
\hline $21-25$ & $30(75 \%)$ & $5(12.5 \%)$ \\
\hline $26-30$ & $0(0 \%)$ & $5(12.5 \%)$ \\
\hline $31-35$ & $0(0 \%)$ & $2(5 \%)$ \\
\hline$>36$ & $0(0 \%)$ & $24(60 \%)$ \\
\hline $\begin{array}{l}\text { Total amount of } \\
\mathrm{MgSO}_{4} \text { given } \\
(\mathrm{Gms})\end{array}$ & $21.1 \pm 2.71$ & $33.6 \pm 7.37$ \\
\hline $\mathrm{P}$ value & & $<0.001$ \\
\hline
\end{tabular}

In patients treated with Dhaka regime $23(57.5 \%)$ patients underwent LSCS, 13 (32.5\%) patients had spontaneous vaginal deliveries while in $2(5 \%)$ patients outlet forceps and in 1 patient ventouse was applied for foetal distress.

Table 4: Mode of Delivery in both the group.

\begin{tabular}{|lll|} 
Mode of delivery & $\begin{array}{l}\text { Dhaka regime } \\
(\mathbf{n = 4 0})\end{array}$ & $\begin{array}{l}\text { Pritchard } \\
\text { regime }(\mathrm{n}=40)\end{array}$ \\
\hline LSCS & $23(57.5 \%)$ & $27(67.5 \%)$ \\
\hline Vaginal, unaided & $13(32.5 \%)$ & $10(25 \%)$ \\
\hline $\begin{array}{l}\text { Forceps/ventouse } \\
\text { application }\end{array}$ & $3(7.5 \%)$ & $2(5 \%)$ \\
\hline Hysterectomy & $1(2.5 \%)$ & $1(2.5 \%)$ \\
\hline
\end{tabular}

In patients treated with Pritchard regime $27(67.5 \%)$ underwent LSCS, 10 (25\%) patients delivered naturally while $2(5 \%)$ had assisted vaginal deliveries. One patient in both the group underwent hysterectomy due to uncontrolled PPH during caesarean section (Table 4).

Table 5: Maternal complications in the two groups.

\begin{tabular}{|llll|}
\hline $\begin{array}{l}\text { Maternal } \\
\text { complications }\end{array}$ & $\begin{array}{l}\text { Dhaka } \\
\text { regime } \\
(\mathbf{n = 4 0 )}\end{array}$ & $\begin{array}{l}\text { Pritchard } \\
\text { regime } \\
(\mathbf{n = 4 0 )}\end{array}$ & $\begin{array}{l}\text { P } \\
\text { value }\end{array}$ \\
\hline $\begin{array}{l}\text { Loss of knee jerk } \\
\text { Oliguria }\end{array}$ & $4(15 \%)$ & $10(25 \%)$ & 0.401 \\
\hline $\begin{array}{l}\text { Abruptio placentae } \\
\text { Postpartum } \\
\text { haemorrhage }\end{array}$ & $6(10 \%)$ & $3(7.5 \%)$ & 0.737 \\
\hline HELLP & $6(15 \%)$ & $8(20 \%)$ & 0.769 \\
\hline Acute renal failure & $1(2.5 \%)$ & $1(2.5 \%)$ & 1 \\
\hline Pulmonary oedema & $4(10 \%)$ & $2(5 \%)$ & 0.675 \\
\hline DIC & $1(2.5 \%)$ & $2(5 \%)$ & 1 \\
\hline $\begin{array}{l}\text { Cerebrovascular } \\
\text { accident }\end{array}$ & $1(2.5 \%)$ & $1(2.5 \%)$ & 1 \\
\hline Maternal mortality & $1(2.5 \%)$ & $2(5 \%)$ & 1 \\
\hline
\end{tabular}

There was no significant difference in maternal complications in both the groups. One patient died in Group A due to cerebrovascular accident and 2 patients in group B due to DIC and cerebrovascular accident respectively (Table 5).

Table 6: Neonatal outcomes in the two groups.

\begin{tabular}{|llll|}
\hline Outcome & $\begin{array}{l}\text { Dhaka } \\
\text { regime }\end{array}$ & $\begin{array}{l}\text { Pritchard } \\
\text { regime }\end{array}$ & $\begin{array}{l}\text { P } \\
\text { value }\end{array}$ \\
\hline $\begin{array}{l}\text { Mean birth } \\
\text { weight }\end{array}$ & $2.03 \pm 0.49$ & $2.13 \pm 0.53$ & 0.384 \\
\hline $\begin{array}{l}\text { Live births } \\
\begin{array}{l}\text { Intra partum } \\
\text { death }\end{array}\end{array}$ & $27(67.5 \%)$ & $25(62.5 \%)$ & \\
\hline $\begin{array}{l}\text { Intra uterine } \\
\text { death }\end{array}$ & $6(15 \%)$ & $3(7.5 \%)$ & \\
\hline $\begin{array}{l}\text { Neonatal } \\
\text { mortality }\end{array}$ & $3(7.5 \%)$ & $2(5 \%)$ & 0.547 \\
\hline $\begin{array}{l}\text { Overall perinatal } \\
\text { mortality }\end{array}$ & $13(32.5 \%)$ & $15(37.5 \%)$ & 0.815 \\
\hline $\begin{array}{l}\text { Apgar score } \\
\text { 8-10 (normal) }\end{array}$ & $14(51.85 \%)$ & $9(37.5 \%)$ & \\
\hline $\begin{array}{l}\text { 6-7 (mild } \\
\text { asphyxia) }\end{array}$ & $5(18.51 \%)$ & $8(33.33 \%)$ & \\
\hline $\begin{array}{l}\text { 4-5 (moderate } \\
\text { asphyxia) }\end{array}$ & $6(22.22 \%)$ & $5(20 \%)$ & \\
\hline $\begin{array}{l}\text { 0-3 (severe } \\
\text { asphyxia) }\end{array}$ & $2(7.4 \%)$ & $3(12.5 \%)$ & \\
\hline
\end{tabular}

Six $(15 \%)$ cases in Group A and $10(25 \%)$ cases in Group $\mathrm{B}$ were already had IUD at the time of admission. Mean birth weight in Group A and Group B was $2.03 \mathrm{~kg}$ and $2.13 \mathrm{~kg}$ respectively. Apgar score, neonatal death rate and overall perinatal death were comparable in both the groups. Neonatal mortalities were mainly due to birth asphyxia, respiratory syndrome and septicemia (Table 6).

\section{DISCUSSION}

In the present study, 22 patients in Group $\mathrm{A}$ and 20 patients in Group B were between 20-25 years of age, while one patient in Group A and 2 patients in group B were below 20 years of age. According to Georgia A, maternal age of less than 20 years is the strongest risk factor for eclampsia. ${ }^{9}$ Studies by Kameshwari, Sardesai et al and Biswas et al reported that $60 \%, 46 \%$ and $42 \%$ of cases were below 20 years of age respectively. ${ }^{5,10,11}$ This high incidence in teenagers may be related to subnormal development of uterine vasculature.

In the present study, we observed that the majority of cases belonged to rural area and were from middle or lower socio-economic group with body weight much lower than women from higher socio-economic group. Seventy four percent of women had body weight less than 50 kilograms at the time of admission. Jana $\mathrm{N}$ et al 
measured weight and showed most women were of small stature, with a mean height of $151 \pm 7.0 \mathrm{~cm}$, a mean weight of $41.7 \pm 5.3 \mathrm{~kg}$, and a mean body mass index of $19.3 \pm 2.1 .{ }^{12}$ Bangal et al observed that $70 \%$ of women had body weight less than 50 kilograms at the time of admission. ${ }^{13}$ Eclampsia is diseases of primigravida which was seen in this study as well, Bangal et al, Pritchard et al and Sardesai et al in their studies observed $80 \%, 75 \%$, and $79 \%$ of eclampsia cases in primigravidas respectively. ${ }^{4,5,13}$ Majority of patients in present study were ante partum eclampsia that is also observed by Dorsett $\mathrm{L}$ et al and Menon K et al. ${ }^{14,15}$

The yardstick used to measure the efficacy of magnesium sulphate was the number of convulsions that occurred after the patient was started on magnesium sulphate. 2 patients in Group A and one patient in Group B had recurrence of convulsion after the loading dose, which was tried to control by an additional single dose of $2 \mathrm{gm}$ i.v slowly magnesium sulphate in both the groups. In Group A, one case responded but another case again developed convulsion 20 minutes after giving single 2 gm i.v dose of $\mathrm{MgSO}_{4}$, and shifted immediately to standard Pritchard regime schedule. In Group B, in spite of giving $2 \mathrm{gm}$ i.v dose of $\mathrm{MgSO}_{4}$, further convulsion developed after 30 minute, for which i.v phenytoin was given. Failure rate in both the group was $2.5 \%$. None of the patients with impending eclampsia in both the groups developed the seizure during entire treatment period.

Sibai et al reported recurrence rate of $1 \%$ out of 1158 patients who received magnesium sulphate by Pritchard regimen. ${ }^{16}$ Pritchard et al reported $12.1 \%$ recurrence in 83 patients treated by magnesium sulphate. ${ }^{4}$ Sibai et al reported $14.2 \%$ recurrence using Pritchard regimen. ${ }^{17}$ In eclampsia collaborative trial recurrence rate was $5.7 \%$. In a study by Sardesai et al, the recurrence rate was $7.89 \%$ with low dose regimen. ${ }^{5}$ In a study by Begum et al, there was one case of recurrence out of 65 patients who received low dose magnesium sulphate. ${ }^{18}$

$10(25 \%)$ patients in Group B compared to $6(15 \%)$ patients in Group A experienced loss of deep tendon reflexes. $6(15 \%)$ patients developed oliguria in Pritchard regime group as compared to $4(10 \%)$ patients in Dhaka regime of $\mathrm{MgSO}_{4}$. Therefore maintenance dose of $\mathrm{MgSO}_{4}$ was skipped in these patients. In the low dose magnesium sulphate regimen by Begum and colleagues, Mahajan and colleague, maintenance dose was omitted in $9 \%$ and $41 \%$ respectively due to loss of DTR. ${ }^{7,18}$ Study by Shilva and colleagues showed loss of DTR was $8 \%$ and $32 \%$ in Low dose and standard dose group respectively $(\mathrm{p}=0.03) .{ }^{19}$

Mean serum magnesium level on absence of knee jerk in Group A was $4.35 \pm 0.15 \mathrm{mg} / \mathrm{dl}$ and $4.73 \pm 0.12 \mathrm{mg} / \mathrm{dl}$ in Group B. The value of mean serum magnesium at the time of oliguria in Group A and B were $5.0 \pm 0.28 \mathrm{mg} / \mathrm{dl}$ and $5.23 \pm 0.15 \mathrm{mg} / \mathrm{dl}$ respectively. However, serum magnesium in both the groups remains within the normal therapeutic range of $\mathrm{MgSO}_{4}$ therapy (4.2 to $8.4 \mathrm{mg} / \mathrm{dl}$ ) and hence magnesium toxicity was not observed in either group. Therefore, for judging toxicity, clinical monitoring seems more feasible than serum magnesium levels and the former is always stringently required for Pritchard regime therefore restricting its use in resource poor setting with inadequate manpower. In present study mean serum magnesium levels at loss of DTR was below levels that would produce toxicity and this could be explained by higher sensitivity of low BMI women to magnesium toxicity.

In the present study, the mean total dose of magnesium sulphate administered in Dhaka regimen $(21.1 \pm 2.71 \mathrm{gms})$ is significantly lower than that administered for Pritchard regimen $(33.6 \pm 7.37 \mathrm{gms}$ ) ( $\mathrm{p}$ value $<0.001$ ). Jana $\mathrm{N}$ et al observed in his study found that total dose of magnesium sulphate administered $23.9 \pm 4.3 \mathrm{gm}$ was significantly lower than that administered during the collaborative eclampsia trial $(\mathrm{P} \leq 0.001){ }^{12}$ The reported maternal mortality due to eclampsia ranges from $0.4 \%$ to $14 \%$ depending on the severity of the organ damage and delay in initiation of treatment. In the present study, there was one maternal mortality in Group A due to cerebrovascular accident and two patients died in Group B due to DIC and cerebrovascular accident respectively. Sardesai etal reported maternal mortality as $2.63 \%$, that in the collaborative eclampsia trial with Pritchard regime was $3.8 \%$ and $5.2 \% .^{1,5}$

In the present study, the perinatal mortality in Group A and Group B was $32.5 \%$ and $37.5 \%$ respectively. Neonatal outcome depends on severity of associated intrauterine growth retardation (IUGR), gestational age, birth weight and the level of facilities in neonatal intensive care unit. Desai et al reported perinatal mortality of $33.83 \%$ with Pritchard regime. ${ }^{20}$ Biswas et al in his study of eclampsia cases, reported perinatal mortality of $24.07 \% .{ }^{11}$ Sardesai et al by using low dose magnesium sulphate therapy reported a perinatal mortality of $25.87 \% .^{5}$ Maru et al in her study reported perinatal mortality of $20 \%$ with low dose magnesium sulphate regime and $37.14 \%$ with Pritchard regime. ${ }^{21}$

\section{CONCLUSION}

In the present study, low dose $\mathrm{MgSO}_{4}$ regime (Dhaka regime) was as effective as Pritchard regime in controlling eclamptic fits and preventing its recurrence with comparable maternal and perinatal outcome. Signs of impending toxicity of magnesium sulphate were found significantly more on giving standard Pritchard regime. From these observations it seems that Dhaka regime can be safely used among Indian women with low BMI and in resource poor settings where facilities for proper monitoring are lacking.

\section{ACKNOWLEDGMENTS}

Authors would like to acknowledge Dr. Abha Rani Sinha, Associate professor, Department of Obstetrics and 
Gynaecology, Patna Medical College and Hospital, Patna for completion of present task. Authors also grateful to Dr. Chandra Prakash, juniors, staff nurses for their help in carrying out this study.

\section{Funding: No funding sources}

Conflict of interest: None declared

Ethical approval: The study was approved by the Institutional Ethics Committee

\section{REFERENCES}

1. The Eclampsia Trial Collaborative Group. Which anticonvulsant for women with eclampsia? Evidence from the Collaborative Eclampsia Trial. Lancet 1995;345:1455-63.

2. Begum R, Begum A, Johanson R, Ali MN, Akhtar S. A low dose (Dhaka) magnesium sulphate regimen for eclampsia: clinical findings and serum magnesium levels. Acta Obstet Gynecol Scand. 2001;80(11):998-1002.

3. Mahajan NN, Thomas A, Soni RN, Gaikwad NL, Jain SM. Padhar regime-A low dose magnesium sulphate treatment for eclampsia. Gynecol Obstet Invest. 2008;30:20.

4. Pritchard JA. The use of magnesium ion in the management of eclamptogenic toxaemia. Surgical Gynecol Obstet. 1955;100(2):131-40.

5. Sardesai SP, Patil A, Maira S, Patil U. Low dose magnesium sulphate therapy for eclampsia and imminent eclampsia: Regime tailored for Indian women. Int J Gynecol Obstet. 2000;70:B45-6.

6. Flower CA. Magnesium sulphate in toxaemia of pregnancy-New dosage schedule based on body weight. Obstet Gynecol. 1962;19:315-27.

7. Mahajan NN, Thomas A, Soni RN, Gaikwad NL, Jain SM. Padhar Regime-a low dose magnesium sulphate treatment for eclampsia. Gynecol Obstet Invest. 2009;67:20-4.

8. Malapaka SVN, Ballal PK. Low-dose magnesium sulphate versus Pritchard regimen for the treatment of eclampsia imminent eclampsia. Intern J Gynecol Obstet India. 2011;115:70-2.

9. Saftlas AF, Olson DR, Franks AL, Atrash HK, Pokras R. Epidemiology of preeclampsia and eclampsia in the United States, 1979-1986. Am J Obstet and Gynecol. 1990;163:460-5.
10. Devi K. Review of Eclampsia. J Obstet Gynecol India. 1976;26:53-8.

11. Biswas A, Modak R, Baksi S, Biswas S. Epidemiological study of eclampsia in a referral teaching hospital. 2005;103(6):323-4.

12. Jana N, Dasgupta S, Das AK, Santra D, Samanta B. Experience of a low dose magnesium sulphate regimen for the management of eclampsia over a decade. Int J Gynecol Obstet. 2013;122(1):13-17.

13. Bangal V, Kwatra A, Raghav S and Jadhav S. Low dose magnesium sulphate regime for Eclampsia. Pravara Med Rev. 2009;4(3):13-5.

14. Dorset L. Intramuscular injection of magnesium sulphate for control of convulsion in Eclampsia; Am J Obstet Gynecol. 1926;11:227-31.

15. Krishna M. The curative treatment of Eclampsia- a critical review. J Obstet Gynecol India. 1958;9:1-15.

16. Sibai BM, Mc Cubbin JH, Anderson GD, Lipshitz J, Dilsts PV Jr. Eclampsia: Observations from 67 recent cases. Obstet Gynecol. 1981;58(5):609-13.

17. Sibai BM. Magnesium sulphate is the ideal anticonvulsant in preeclampsia eclampsia. Am J Obstet Gynecol. 1990;162:1141-5.

18. Begum R, Begum A, Johanson R, Ali MN and Akhtar SA low dose ('Dhaka') magnesium sulphate regime for Eclampsia clinical findings and serum magnesium levels. Acta Obstet Gynecol Scand. 2001;80:998-1002.

19. Shilva, Saha SC, Kalra J, Prasad R. Safety and efficacy of low dose magnesium sulphate in the treatment of eclampsia. Int $\mathbf{J}$ Gynecol Obstet. 2007;97(2):150-1.

20. Desai P, Badheka H, Barbaiya M. Changes in perinatal outcome due to magnesium sulphate in eclampsia. J Obstet Gynecol India. 1995;45:732-5.

21. Laxmi M, Neha G. Can we improve maternal and foetal outcome in eclampsia by low dose magnesium sulphate? Asian J Obstet Gynecol Practice. 2011;1:17-20.

Cite this article as: Ranjana, Sinha AR, Prakash C. A comparative study of low dose magnesium sulphate (Dhaka regime) and Pritchard regime for the management of impending eclampsia and eclampsia. Int J Reprod Contracept Obstet Gynecol 2017;6:2180-5. 